\title{
Informatização do processo de seleção de bolsistas de assistência estudantil: a experiência do IFMG
}

\author{
Computerization of the student assistance scholarships selection process: the IFMG experience
}

Computerización del proceso de selección de becas de asistencia al estudiante: la experiencia en el

IFMG

\author{
Recebido: 07/01/2021 | Revisado: 10/01/2021 | Aceito: 12/01/2021 | Publicado: 13/01/2021 \\ Eduardo Cardoso Melo \\ ORCID: https://orcid.org/0000-0002-1323-5859 \\ Instituto Federal de Educação, Ciência e Tecnologia de Minas Gerais, Brasil \\ E-mail: eduardo.melo@ifmg.edu.br \\ Gabriel da Silva \\ ORCID: https://orcid.org/ 0000-0001-9784-5517 \\ Instituto Federal de Educação, Ciência e Tecnologia de Minas Gerais, Brasil \\ E-mail: gabriel.silva@ifmg.edu.br \\ Paulo César Lourenço da Silva \\ ORCID: https://orcid.org/ 0000-0002-9266-3340 \\ Instituto Federal de Educação, Ciência e Tecnologia de Minas Gerais, Brasil \\ E-mail: paulo.lourenco@ifmg.edu.br
}

\begin{abstract}
Resumo
Os órgãos governamentais vêm buscando maneiras de aprimorar a sua eficiência com o apoio de recursos tecnológicos, ampliando assim o acesso da população a diversos serviços que, até então, demandavam presença física em determinados locais. O presente artigo é apresentado neste contexto de inovações no governo eletrônico, em especial, porque delineia e apresenta os resultados do projeto de informatização das atividades relacionadas ao processo de seleção de estudantes bolsistas do Instituto Federal de Minas Gerais (IFMG). Trata-se de uma pesquisa que apresenta um novo produto a partir de um experimento exploratório conduzido como um estudo de caso no âmbito desta instituição. A execução do processo com o suporte do Sistema de Informação construído gerou, como principais ganhos, a redução em cerca de $51 \%$ no tempo médio de publicação dos resultados de editais, maior rapidez na liberação dos recursos financeiros para estudantes com comprovada vulnerabilidade socioeconômica e a otimização de recursos humanos envolvidos com as análises documentais. Finalmente, aumentos de eficiência na execução de tarefas em conjunto com o incremento na satisfação dos envolvidos são resultados que devem ser amplamente divulgados para que a administração pública seja mais efetiva na condução de projetos de inovação tecnológica.
\end{abstract}

Palavras-chave: Governo eletrônico; Sistemas de informação; Gestão informatizada; Assistência estudantil.

\begin{abstract}
Government agencies have been looking for ways to improve their efficiency with the support of technological resources, thus expanding the population's access to various services that, until then, demanded physical presence in certain locations. This article is presented in this context of innovations in electronic government, in particular, because it outlines and presents the results of the computerization project of activities related to the selection process of scholarship students at the Federal Institute of Minas Gerais (IFMG). This is a research that presents a new product from an exploratory experiment conducted as a case study within this institution. The execution of the process with the support of the built Information System generated, as main gains, the reduction of about $51 \%$ in the average time of publication of the results of public notices, faster release of financial resources for students with proven socioeconomic vulnerability and the optimization of human resources involved with document analysis. Finally, increases in efficiency in the execution of tasks in conjunction with the increase in the satisfaction of those involved are results that must be widely disseminated so that the public administration is more effective in conducting technological innovation projects.
\end{abstract}

Keywords: Electronic government; Information systems; Computerized management; Student assistance.

\section{Resumen}

Las agencias gubernamentales han estado buscando formas de mejorar su eficiencia con el apoyo de recursos tecnológicos, ampliando así el acceso de la población a diversos servicios que, hasta entonces, demandaban presencia física en determinadas localidades. Este artículo se presenta en este contexto de innovaciones en gobierno electrónico, en particular, porque delinea y presenta los resultados del proyecto de informatización de actividades relacionadas con 
el proceso de selección de estudiantes becados en el Instituto Federal de Minas Gerais (IFMG). Se trata de una investigación que presenta un nuevo producto de un experimento exploratorio realizado como estudio de caso dentro de esta institución. La ejecución del proceso con el apoyo del Sistema de Información construido generó, como principales ganancias, la reducción de alrededor del $51 \%$ en el tiempo promedio de publicación de los resultados de los avisos públicos, la liberación más rápida de recursos financieros para estudiantes con probada vulnerabilidad socio-económica y la optimización de los recursos humanos involucrados en el análisis de documentos. Finalmente, los incrementos en la eficiencia en la ejecución de tareas en conjunto con el aumento en la satisfacción de los involucrados son resultados que deben ser ampliamente difundidos para que la administración pública sea más efectiva en la conducción de proyectos de innovación tecnológica.

Palabras clave: Gobierno electrónico; Sistemas de información; Gestión informatizada; Asistencia al estudiante.

\section{Introdução}

O mundo atual é, em grande parte, baseado nas interações com equipamentos eletrônicos. Seja para tratar de questões particulares ou profissionais, as pessoas podem resolver diversas questões do seu cotidiano sem sequer sair de casa, bastando para isso um dispositivo conectado à internet e um software aplicativo com funcionalidades adequadas para cada necessidade. A utilização de computadores e da internet na sociedade está tão difundida que muitas tarefas dos indivíduos somente podem ser feitas por estes meios, pois as empresas que antes eram sempre baseadas em atendimento em localização física não mais apresentam esta característica, possuindo apenas um ambiente virtual (acessível por meio de um dispositivo eletrônico) para comunicação e interação com seus clientes e usuários.

Neste contexto de utilização maciça de recursos eletrônicos, com capacidade de computar e se comunicar por meio da internet, merece destaque o papel da Tecnologia da Informação (TI), pela concepção e desenvolvimento de soluções capazes de prover os meios adequados para que muitas das atividades antes realizadas manual e presencialmente passassem a ser disponibilizadas em um meio que ofereça facilidade e comodidade aos usuários. É importante ressaltar que a TI não trata apenas de elementos físicos das máquinas, mas envolve principalmente aspectos lógicos que permitem seu funcionamento, cujo exemplo mais conhecido talvez sejam os softwares.

Ao mesmo tempo em que as tecnologias da informação passaram a ser acessíveis a um número maior de pessoas, as empresas necessitaram se adaptar para o que, até então, era considerado um novo modelo de negócio. Desde a simples utilização de computadores em seus ambientes, passando pela informatização de seus processos em Sistemas de Informação (SI) e culminando na oferta de produtos e serviços na internet, as empresas precisaram reinventar sua forma de atuação e gestão, considerando principalmente sua sobrevivência em um contexto dominado por novas tecnologias eletrônicas.

O setor público no Brasil, infelizmente, ainda não apresenta a mesma maturidade para utilização de recursos tecnológicos do que aquela experimentada pela iniciativa privada. A burocracia estatal, seja ela em qualquer esfera (nacional, estadual ou municipal), ainda gera dificuldades tanto para cidadãos quanto para empresas. Mesmo sendo notada certa evolução recente na oferta de serviços eletrônicos pelos Governos, conforme apresentado por Camões, Severo e Cavalcante (2017), Dias, Sano e Medeiros (2019), Oliveira (2017) e Cavalcante e Camões (2015), tais iniciativas se mostram insuficientes diante de demandas pontuais de determinados órgãos públicos e da sociedade como um todo.

O Instituto Federal de Educação, Ciência e Tecnologia de Minas Gerais (IFMG) é uma instituição pública de ensino pertencente à Rede Federal de Educação Profissional e Tecnológica do Ministério da Educação, cujo principal objetivo é ofertar educação gratuita de qualidade em cursos de diferentes níveis, especialmente técnicos e superiores. A unidade administrativa (Reitoria) está localizada em Belo Horizonte/MG, sendo que os campi estão distribuídos em outras 18 (dezoito) cidades do estado. Em 2020 estavam matriculados mais de 10.000 alunos na instituição. Dentro da estrutura organizacional do IFMG existe um setor denominado Diretoria de Assuntos Estudantis, integrante da Pró-reitoria de Ensino (PROEN), o qual é responsável por cuidar de assuntos relacionados com a assistência estudantil dos alunos, sendo uma de suas atribuições a concessão de benefícios (principalmente financeiros) para aqueles que apresentam comprovada vulnerabilidade social. A 
definição dos alunos aptos ao recebimento deste auxílio é feita a partir da publicação de editais específicos para cada campus, seguindo critérios e regras bem definidas de análise socioeconômica válidas em toda a instituição. Mais de $60 \%$ dos alunos matriculados no IFMG participaram desses editais nos anos de 2017 e 2018 (IFMG, 2020a).

De acordo com IFMG (2020b), em 2011 a instituição implementou o Programa de Assistência Estudantil (PAE), que pode ser entendido como um conjunto de princípios e diretrizes para orientação do desenvolvimento de ações que busquem democratizar o acesso a e a permanência dos estudantes na Instituição. Para participar dos programas de caráter socioeconômico o aluno deve comprovar sua situação de vulnerabilidade, a fim de que a mesma possa ser avaliada pelo Núcleo de Assistentes Sociais do Instituto (NASIFMG).

Desde o início do programa a análise documental era feita de forma manual pelo NASIFMG, trazendo consideráveis prejuízos para o processo como um todo. Cada estudante inscrito nos editais publicados apresentava ao NASIFMG a respectiva documentação comprobatória de sua situação para que pudesse ser analisada. Além do preenchimento de um questionário socioeconômico com mais de 60 (sessenta) páginas, o aluno entregava em um envelope as cópias de todos os seus documentos e comprovações conforme exigido pelo edital. A documentação de cada estudante gerava um envelope contendo, em média, 55 páginas. A noção do volume de papel trafegado, apenas neste início do processo, pode ser obtida a partir de um simples cálculo feito com os dados do campus com o maior número de alunos participantes em 2018, onde foram protocoladas 553 inscrições. Considerando esses quantitativos, foram mais de 30.000 páginas de documentos analisadas em um único campus na etapa inicial do processo.

Outro trabalho manual consistia na elaboração de planilhas eletrônicas a partir da digitação das informações prestadas em papel pelos estudantes inscritos no edital. Esta atividade era desenvolvida ao longo da análise do processo individual do estudante, de maneira que ao final da etapa cada campus gerava uma planilha com os dados de seu edital e enviava para o setor de Assuntos Estudantis na Reitoria. Neste momento, eram feitas novas análises sobre os dados recebidos e formalizado o resultado final com a indicação de quais alunos estavam aptos para o recebimento de algum auxílio. Os processos indeferidos por documentação incompleta retornavam aos campi de origem e os estudantes poderiam solicitar recurso sobre a avaliação, bem como complementar alguma documentação faltante. Esta ação só era possível a partir da publicação do resultado preliminar do edital, devendo então o estudante agendar uma entrevista presencial com o Assistente Social para verificar quais eram as pendências do seu processo. Somente depois desta entrevista o aluno encaminharia os documentos faltantes para que pudessem ser novamente avaliados e, se fosse o caso, modificado o resultado final do edital. Outro problema percebido no preenchimento desta planilha era a possibilidade de erro de digitação ou de preenchimento por parte do servidor responsável, o que, muitas vezes, era notado apenas no momento da entrevista presencial.

Nesta realidade, o tempo entre a divulgação do edital e sua finalização chegava a durar mais de 100 (cem) dias corridos (dependendo do número de inscritos). Ao considerarmos mais algum prazo para a efetivação do pagamento do auxílio econômico, muitos estudantes com grande vulnerabilidade simplesmente não conseguiam se manter na instituição até o início do recebimento do benefício, chegando a evadir-se do curso e, consequentemente, da instituição.

Este artigo descreve como foi desenvolvido o projeto de informatização, com apoio de um sistema de informação, do processo de análise socioeconômica promovido pelo IFMG para a seleção de estudantes aptos a receberem auxílios específicos dentro do contexto do Programa de Assistência Estudantil da instituição, bem como apresentar os principais resultados obtidos a partir da utilização da solução proposta.

\section{Governo Eletrônico (e-government)}

No entendimento de Dias et al. (2019), o governo eletrônico pode ser compreendido como uma ferramenta disponível para que os membros da administração pública possam melhorar e dinamizar diversos aspectos da gestão, em especial no que 
concerne ao relacionamento entre o governo e seus parceiros, como empresas, cidadãos, empregados e outras unidades da sua própria estrutura, contando com o auxílio direto de recursos de Tecnologia da Informação e Comunicação (TIC).

Lacerda e Helal (2019) indicam que as ações relacionadas com o governo eletrônico devem ser balizadas pelo emprego de modernos recursos de TIC com o objetivo final de promover a democratização no acesso à informação por qualquer indivíduo ou organização interessada, bem como proporcionar formas de ampliação das discussões ao mesmo tempo em que consegue prestar os serviços públicos aos cidadãos com efetividade e eficiência.

Kon (2019) observa que assuntos relacionados ao governo eletrônico vêm sendo discutidos desde a década de 1990 em diversos países, tendo por pano de fundo a utilização de TICs como base para a disponibilização e execução de serviços pela administração pública. A autora indica ainda que os Sistemas de Informação possuem papel de destaque na condução do desenvolvimento econômico de várias nações, tanto em setores privados quanto naqueles considerados públicos, fazendo com que o governo eletrônico se mantenha como importante item da agenda de gestores que buscam modernizar suas administrações apoiados na tecnologia.

Rabelo e Viegas (2012) fazem uma válida ressalva ao afirmar que o conceito de governo eletrônico não pode ser compreendido apenas como sendo a automatização de processos ou a mera disponibilização de serviços virtuais pela administração pública aos cidadãos e empresas, mas o seu entendimento precisa ser amplificado a fim de que este tema seja visto como uma nova forma empregada pelo governo para cumprir efetivamente o papel do Estado.

No Brasil, a adoção pela administração pública de recursos relacionados com o governo eletrônico passou a ter maior representatividade a partir de 2012 com o lançamento da Estratégia Nacional de Ciência, Tecnologia e Inovação, cujo objetivo principal era ser um conjunto de políticas públicas que suportassem a melhoria das condições de desenvolvimento da ciência e tecnologia no país. Como continuidade desta iniciativa, em 2016 o governo federal lançou a Estratégia de Governo Digital (EGD) propondo uma série de metas e ações para o período de 2016 a 2019, focada em três eixos denominados: acesso à informação, prestação de serviços e participação social. No final deste período, mais de 50\% dos serviços do governo federal estavam disponíveis em versão digital (Dias, et al., 2019). Em 2020 foi apresentado o planejamento para o período de 2020 a 2022, tendo como base o estabelecimento de diversos princípios, objetivos e iniciativas para a transformação do governo com $\mathrm{o}$ apoio das tecnologias digitais. $\mathrm{O}$ Decreto $\mathrm{n}^{\circ} 10.332$ foi publicado para legitimar a iniciativa e servir também como meio de divulgação dos ousados objetivos do plano (Governo, 2020).

Considerando o contexto do trabalho apresentado neste artigo em conjunto com o entendimento sobre governo eletrônico, é possível indicar que se trata de uma forma clara de atendimento a uma das mais importantes premissas dos órgãos públicos, conhecida como eficiência. Para Albiero (2018), a eficiência na administração pública está diretamente ligada à capacidade desta de cumprir ampla e satisfatoriamente as demandas sociais que lhe são cabíveis, sempre mantendo o equilíbrio entre a utilização de meios adequados com o menor dispêndio econômico possível para cada ocasião.

\section{Sistemas de Informação (SI)}

O termo Sistemas de Informação possui diversas interpretações e conceituações construídas ao longo do tempo, variando bastante de acordo com a concepção do autor e também a partir da percepção de uso do próprio SI em determinado ambiente. Neste sentido, Nunes (2017) ressalta que tais sistemas podem ser desenvolvidos por empresas dos mais variados tamanhos, fazendo com que seja complexo determinar claramente uma concepção única para o tema. As conceituações apresentadas a seguir objetivam proporcionar o entendimento sintético do termo em relação ao tema central deste artigo, que é a informatização de importante processo do IFMG a partir do desenvolvimento de um sistema de informação.

Laudon e Laudon (2015) apresentam uma das definições mais aceitas para o termo em questão, indicando que os Sistemas de Informação podem ser compreendidos como conjunto de módulos ou componentes relacionados entre si que 
trabalham para suportar o processo de tomada de decisão e gestão das organizações a partir da coleta, processamento, armazenamento e distribuição de informações. Complementando este entendimento, Cortes (2017) ressalta a importância de se construir mecanismos de feedback (retroalimentação) que permitam ao sistema trabalhar também com informações geradas anteriormente por ele mesmo para melhor obtenção de resultados.

Sordi e Meireles (2019) ampliam a compreensão sobre os Sistemas de Informação ao afirmarem que eles podem ser entendidos como um conjunto de softwares que auxiliam no funcionamento das transações de negócios das organizações, bem como ampliam as capacidades de manipulação e tratamento de dados que apresentam alta correlação e são fundamentais para a sobrevivência das empresas em seus segmentos de atuação.

Batista (2013) oportunamente observa que a composição de um SI não se baseia apenas na utilização de computadores, como também de ferramentas concebidas e preparadas para auxiliar na manipulação de todos os dados gerados no ambiente organizacional. Neste sentido, é fundamental que a empresa ou instituição que for trabalhar com um SI igualmente tenha ou desenvolva a preocupação de integrar o seu produto tecnológico às perceptivas organizacionais e de pessoas.

Para Gomes Filho (2018, p. 19), é válido destacar que a conceituação de Sistemas de Informação conhecida como um "[...] conjunto de elementos interdependentes de modo a formar um todo organizado" pode ser aplicada em diversas outras áreas de conhecimento e disciplinas, tais como a medicina, o direito e a biologia, dentre outras. Neste aspecto, o autor indica que a utilização de SIs é viável nas mais variadas áreas e com os mais diversos objetivos, porém é importante que eles apresentem efetiva capacidade de análise de problemas e estejam alinhados aos propósitos organizacionais.

\section{Metodologia}

\subsection{Caracterização da pesquisa}

De acordo com Gerhardt e Silveira (2009), esta pesquisa pode ser classificada quanto à sua abordagem como qualitativa, pois buscou aprofundar a compreensão sobre todas as regras envolvidas com a área de concessão de auxílios socioeconômicos sem a preocupação de gerar e analisar dados essencialmente numéricos. Em relação à natureza, trata-se de uma pesquisa aplicada com intuito de gerar conhecimentos para resolver um problema específico. Quanto aos objetivos, foi realizada uma pesquisa exploratória onde houve a necessidade de obter muitas informações sobre o problema em questão para que, a partir deste conhecimento, fosse possível sugerir e aplicar as mais adequadas resoluções. No que se refere aos procedimentos, entende-se como uma pesquisa documental (por ter utilizado fontes documentais diversas da instituição envolvida) e um estudo de caso (em função do contexto analisado estar vinculado especificamente com o IFMG).

O presente projeto, segundo Wazlawick (2009), pode ser entendido como a "Apresentação de um Produto", no qual se realiza eminentemente uma pesquisa exploratória para a geração de algo novo. Dentro deste estilo também existe o objetivo de compartilhamento de informações relativas ao produto construído a partir da sua disponibilização para uso. Em relação à geração de um novo sistema de informação, como foi proposto, cabe observar que antes do início das atividades a equipe do projeto encontrou dois outros softwares que possuem funcionalidades relacionadas com a informatização do processo de seleção de bolsistas para o setor de Assistência Estudantil. Entretanto, um deles (chamado "SIGAA") fazia parte de um Enterprise Resource Planning (ERP) e não permitia implantação individualizada, enquanto o outro (chamado "SisAE") não contemplava sequer $40 \%$ das funcionalidades necessitadas pelo IFMG.

Considerando os tipos de sistemas de informação apresentados por Laudon e Laudon (2015), o produto gerado por este trabalho pode ser classificado sob variadas óticas. Em relação ao nível organizacional, o escopo está restrito ao setor de Assistência Estudantil do IFMG e às pessoas que, direta ou indiretamente, necessitam do mesmo em suas interações com a instituição. De acordo com o apoio dado pelo sistema, trata-se de um sistema de processamento de transações, sistema de 
informação gerencial, sistema para automação de escritório e também de um sistema de apoio à decisão. Por fim, no que concerne à arquitetura, o produto final apresenta as características de um sistema distribuído.

\subsection{Definições iniciais do projeto}

Optou-se pela utilização do Scrum como metodologia para gestão e planejamento do projeto pela sua simplicidade e facilidade de adaptação. Diversas técnicas foram aplicadas, tais como o trabalho com Backlogs (de produto e de Sprints), cerimônias para discussões e acompanhamento das atividades e iterações para divisão das atividades (Sprints). A ferramenta Trello (acessível em http://www.trello.com) foi utilizada pelos membros da equipe para facilitar o gerenciamento das atividades propostas. Nela foi gerado um quadro com o Backlog do produto contendo todas as funcionalidades previstas para serem desenvolvidas. Quando ocorria o planejamento de um Sprint, as funcionalidades eram movidas do Backlog do produto para o Backlog do Sprint, permitindo que a equipe indicasse aquelas disponíveis, em desenvolvimento, disponíveis para testes ou concluído, conforme apresenta a Figura 1.

Figura 1 - Quadro utilizado para auxiliar no acompanhamento das atividades.

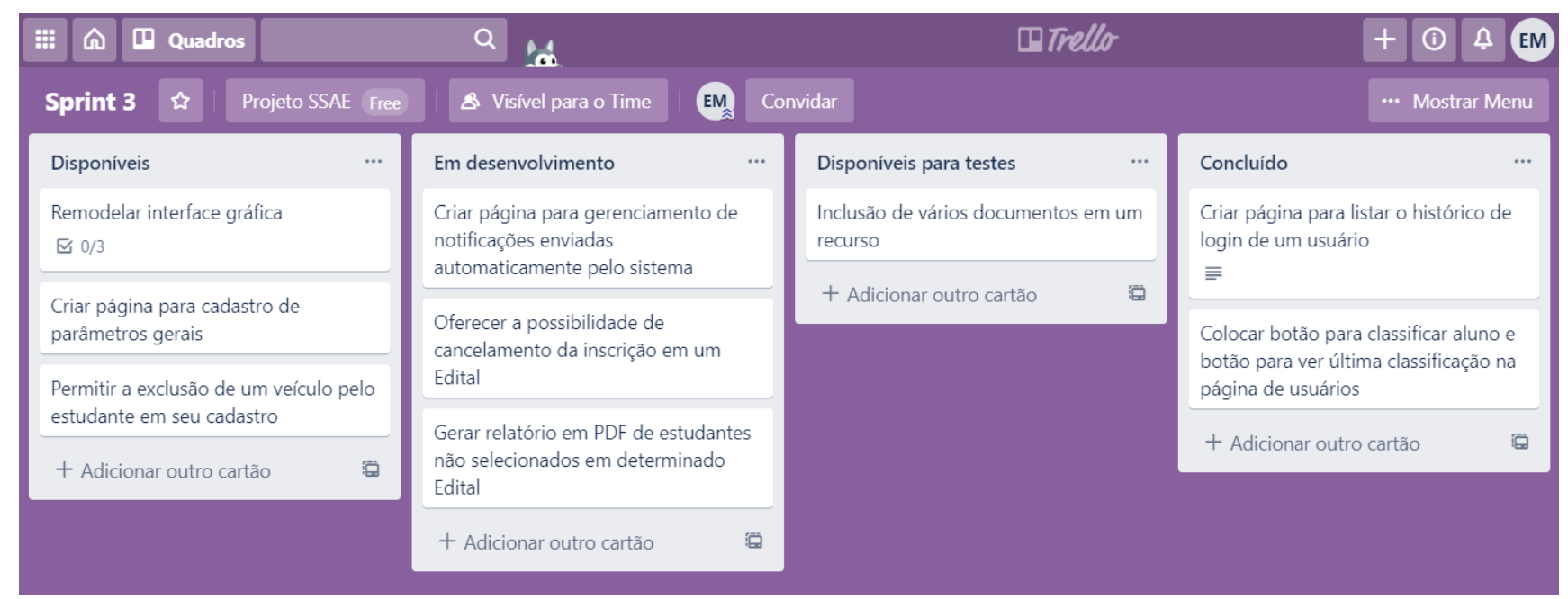

Fonte: Autores (2020).

A equipe do projeto foi composta por um servidor que atua na Diretoria de Assuntos Estudantis do IFMG (atuou como Product Owner), um docente do Núcleo de Computação do campus Bambuí do IFMG (atuou como Scrum Master e na Development Team) e dois discentes do curso de Bacharelado em Engenharia da Computação deste mesmo campus (atuaram na Development Team). As atividades do projeto foram realizadas, em sua maioria, nas dependências do Laboratório de Sistemas Computacionais (LSC) do Grupo de Pesquisas em Sistemas Computacionais (GPSisCom) do IFMG - Campus Bambuí. Alguns espaços da Reitoria do IFMG também foram utilizados em determinados momentos pela equipe do projeto, especialmente no seu início, quando ocorreram os estudos sobre a demanda institucional e o levantamento dos requisitos para o sistema.

Após a formalização do projeto junto à Pró-Reitoria de Extensão do IFMG, as atividades foram iniciadas, em junho de 2018, com a realização de reuniões presenciais e virtuais, objetivando a compreensão do processo de seleção de bolsistas pela Assistência Estudantil. Optou-se pela condução das reuniões com base em entrevistas não estruturadas, nas quais os envolvidos com o processo explicavam como os trabalhos eram conduzidos até então. Os formulários e planilhas disponibilizados e utilizados pelos envolvidos também foram analisados para auxiliar no entendimento da situação e na formulação dos requisitos do sistema. Situações que demandavam compreensão de fluxos de trabalho foram modeladas graficamente com o apoio do 
Diagrama de Transição de Estados da UML (Unified Modeling Language). A partir do conhecimento gerado nessas reuniões, a equipe do projeto realizou a compreensão e o refinamento dos requisitos do sistema, fazendo sua documentação no formato de Estórias de Usuário (Melegati \& Wang, 2019). Na sequência, o modelo físico dos dados foi elaborado para que houvesse uma visão mais compreensiva da estrutura necessária ao armazenamento dos dados do sistema.

Em julho de 2018 o Product Owner realizou a análise dos requisitos documentados, indicando sua aceitação quanto ao escopo compreendido. Em seguida, o restante da equipe do projeto trabalhou na elaboração do Backlog geral do produto, planejando as atividades necessárias em termos de esforço de desenvolvimento para cumprir todo o escopo definido nos requisitos. Ao final desta etapa, o Backlog de produto foi analisado por toda a equipe para definição das prioridades e divisão em Sprints. Considerando a amplitude do projeto e a necessidade de o sistema estar disponível para uso em janeiro de 2019, foi necessária a divisão das atividades em cinco Sprints, cada qual com duração de quatro semanas. As atividades de implementação e configuração do ambiente foram realizadas, então, de agosto a dezembro de 2018, gerando quatro produtos intermediários utilizáveis de software e uma versão final completa e integrada, cumprindo assim o prazo estipulado inicialmente para operacionalização do sistema.

\subsection{Tecnologias utilizadas}

O projeto utilizou grande variedade de tecnologias no seu desenvolvimento, cujas escolhas basearam-se, em grande parte, na experiência prévia dos membros da Development Team e no fato de serem de uso livre, fazendo com que o produto final gerado possa ser modificado por qualquer outra instituição sem a necessidade de pagamentos de licenças. Um repositório privado no GitHub foi criado para que todos os artefatos gerados durante o projeto fossem seguramente armazenados e controlados.

A ferramenta MySQL Workbench, na versão 6.3, foi adotada para a construção do modelo físico dos dados, enquanto o Sistema Gerenciador de Banco de Dados (SGBD) MySQL Community Server Edition, versão 5.7, foi utilizado como repositório de dados em função de sua simplicidade de configuração e manutenção, bem como gratuidade de uso. A construção do sistema foi dividida em duas partes, denominadas front-end e back-end. As interfaces visuais de interação com os usuários (front-end) foram implementadas com as tecnologias HyperText Markup Language (HTML), versão 5, Cascading Style Sheets (CSS 3), JavaScript, Bootstrap 4, jQuery 3 e Asynchronous Javascript and XML (AJAX). A implementação do back-end teve como base a utilização do PHP 7.1, framework CodeIgniter 3 e servidor Apache 2.5.

\section{Resultados e Discussão}

As atividades do primeiro Sprint tiveram como escopo a definição de uma estrutura básica para o projeto em termos de codificação, controle de acessos ao sistema e cadastramento de dados diversos dos estudantes. O código fonte do sistema foi baseado na estrutura proposta pelo framework CodeIgniter, que prevê a utilização do padrão Model-View-Controller (MVC) para organização dos artefatos e separação entre as camadas do software (Gabardo, 2015). As funcionalidades relacionadas com o acesso ao sistema foram implementadas em primeiro lugar, assim permitindo que a entrada no ambiente pudesse ser testada por toda a equipe do projeto, porquanto o perfil do usuário impõe mudanças nas opções de menu disponíveis dentro do sistema. Mais do que um simples local de entrada ao sistema, a página inicial permite que o usuário faça o seu cadastro básico, solicite a geração de uma nova senha (caso tenha esquecido ou perdido a sua), reenvie o link para ativação do seu cadastro ou leia o manual do aluno (caso tenha este perfil). Este manual é composto tanto de explicações textuais sobre cada funcionalidade do sistema quanto de vídeos demonstrando sua operacionalização. A Figura 2 apresenta a página inicial do sistema ao ser acessado em um microcomputador. 
Figura 2 - Página inicial do sistema.

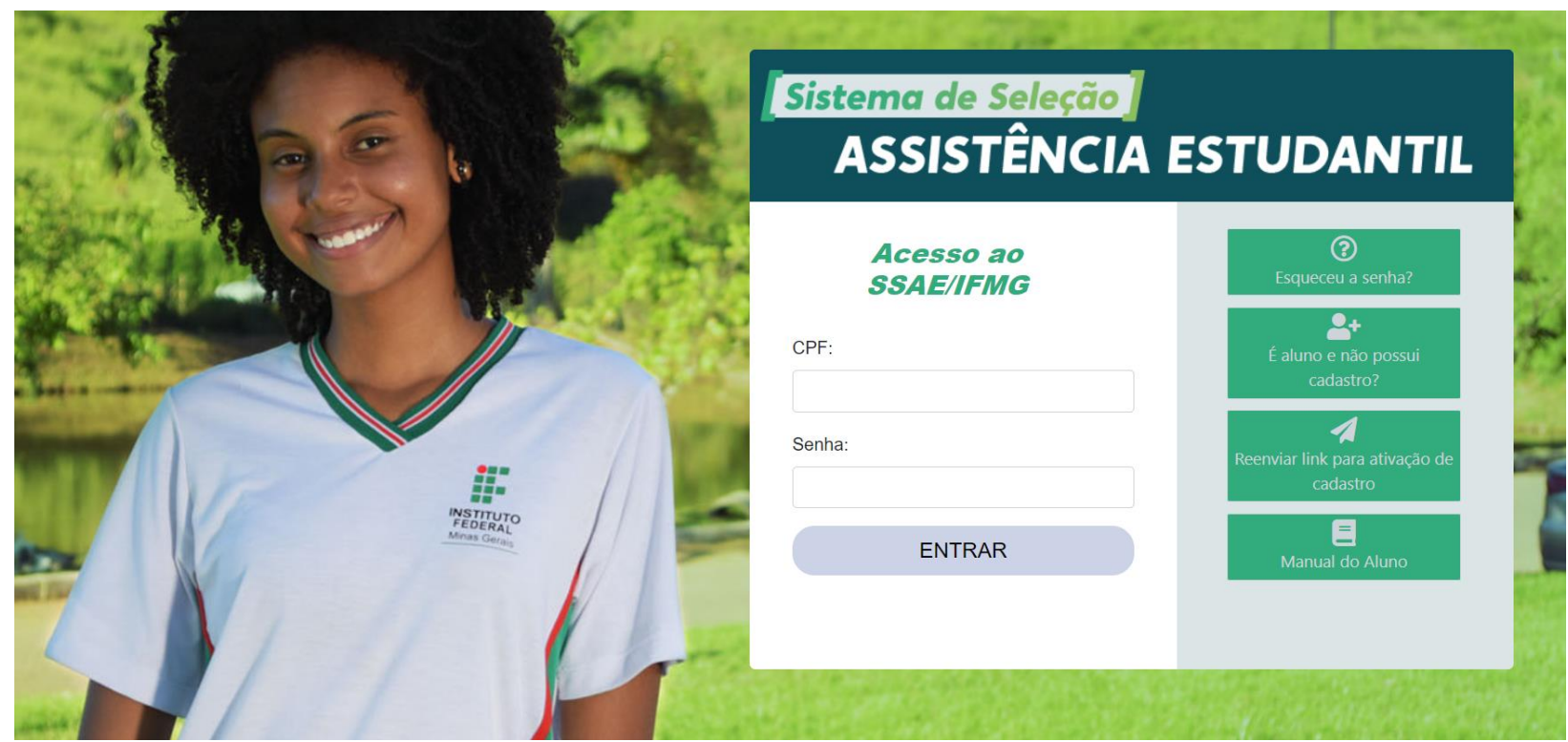

Fonte: Autores (2020).

Ainda dentro do escopo desta primeira iteração, as questões do questionário socioeconômico (antes preenchido em papel pelo estudante) foram disponibilizadas em três agrupamentos no sistema: o primeiro contendo o preenchimento dos dados específicos do estudante, o segundo com os dados dos membros do seu grupo familiar e, por fim, o terceiro com os dados dos seus veículos. Como se tratava de páginas que realizam apenas operações de leitura e escrita de dados, a implementação destas funcionalidades ocorreu sem maiores dificuldades, com exceção da página que apresenta os dados gerais do estudante (cujo fragmento pode ser visualizado na Figura 3), pois era necessário organizar 69 campos de dados a serem preenchidos pelo usuário.

Figura 3 - Fragmento da página de cadastro de dados gerais do estudante.

Identificação do estudante

Nome social: (3)

Obs: não é preciso digitar seu nome de registro aqui, apenas se tiver um nome social.

\begin{tabular}{l|l|l|}
\hline Nascimento: & Telefone: (3) \\
\hline 18/04/1981 & (37) 998148862 \\
\hline Identidade de Gênero: & Identidade de Gênero (outra): & Cor: \\
\hline Masculino & Branca \\
\hline
\end{tabular}

Naturalidade: (?)

Bom Despacho

Possui deficiência? (3)

Não possuo
UF da Naturalidade: (3)

Minas Gerais

Outra deficiência:

Outra deficioncia:

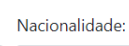

Brasileira

Mãe ou pai desconhecido(s)?

Não
Estado Civil:

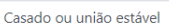

No de filhos vivos da mãe: (?

Dados escolares do estudante

Nivel do curso: (?)

Período de estudo:

Curso: (3)

Graduação

Manhã

Fonte: Autores (2020). 
O primeiro Sprint teve $85 \%$ de conclusão das atividades ao final das quatro semanas previstas de trabalho. Duas situações contribuíram para a não realização de todas as atividades previstas: dificuldades pelos alunos participantes do projeto como Development Team em ajustar suas tarefas às demandas das disciplinas do curso no qual estavam matriculados, além de diversas adequações solicitadas pelo Product Owner nas páginas relacionadas com o cadastro dos dados dos estudantes. A equipe realizou uma reunião de encerramento do Sprint promovendo, então, a retrospectiva de todo o trabalho realizado nesta etapa e identificando situações que poderiam ser melhoradas no decorrer do projeto, bem como ajustes necessários nas funcionalidades já implementadas.

As atividades do segundo Sprint tiveram início tão $\operatorname{logo}$ a versão gerada pela primeira iteração foi aprovada pelo Product Owner. Inicialmente, a Development Team direcionou seus esforços para implementar os ajustes e corrigir os erros identificados na reunião de retrospectiva citada anteriormente. Além disso, foram finalizadas as atividades que estavam originalmente previstas na execução do primeiro Sprint, cujo escopo era a disponibilização de rotinas para gestão dos usuários (cadastro e consulta de histórico de acessos) e a geração de um relatório apresentando todos os dados do cadastro do estudante e de seu grupo familiar.

Em seguida, foi desenvolvida uma das mais importantes funcionalidades do sistema: uma página específica para a gestão dos documentos do estudante. A partir deste recurso de upload de arquivos digitais foi possível eliminar o trânsito de documentos em papel dos estudantes, além de facilitar sobremaneira o acesso aos mesmos pelos membros do NASIFMG durante as análises realizadas na vigência de um edital. No passado, servidores de outros campi do IFMG e até de outras instituições precisaram ser convocados para auxiliar na análise da documentação física dos processos. A partir da implementação do sistema, esta participação pôde ser realizada remotamente, reduzindo os custos com o trabalho presencial na Reitoria do IFMG. A Figura 4 apresenta um fragmento da página de gestão de documentos do estudante e dos membros do seu grupo familiar.

Figura 4 - Fragmento da página de gestão de documentos.

Documentos do estudante

\begin{tabular}{|c|c|c|c|}
\hline Classe/Tipo & Descrição & Situação & Ações \\
\hline Pessoais / Carteira de Identidade/CNH/Certidão de Nascimento & imagem jpg & Não validado & (a) $:=$ \\
\hline Pessoais / CPF & $\mathrm{cpf}$ & Validado & (-) $:=$ \\
\hline Pessoais / Histórico escolar/declaração de escolaridade & Documento de conclusão de curso de graduação & Validado & (e) $:=$ \\
\hline Bens patrimoniais / Certificado de Registro de Veículo (CRV) & & Validado & (-) $:=$ \\
\hline Bens patrimoniais / Comprovante de pagamento de IPVA & ipva & Validado & (a) $:=$ \\
\hline Bens patrimoniais / Valor de referência do veículo (Tabela FIPE) & fipe & Validado & (-) $:=$ \\
\hline Residência / Comprovante de residência & Conta da Cemig & Validado & (1) $:=$ \\
\hline $\begin{array}{l}\text { Filhos de pais separados / Declaração (Anexo VI) de pensão } \\
\text { alimenticia }\end{array}$ & Declaração de pensão alimentícia & Validado & (a) $:=$ \\
\hline Outros documentos / Outros documentos & Comprovante de alguma coisa & Validado & (a) $:=$ \\
\hline
\end{tabular}

Documentos do Grupo Familiar

\begin{tabular}{llll}
\hline Membro & Classe/Tipo & Descrição & Situação \\
\hline Astrogênio Gênio dos Santos Neto & Renda / Cartão do CNPJ & bla bla bla & Validado \\
\hline Astrogênio Gênio dos Santos Neto & Filhos de pais separados / Termo de Separação & Termo de separação & Validado \\
\hline Astrogildo Neves Cardoso & $\begin{array}{l}\text { Bens patrimoniais / Certificado de Registro de Veiculo } \\
\text { (CRV) }\end{array}$ & crv & Validado \\
\hline
\end{tabular}

Fonte: Autores (2020).

Neste Sprint também foi construído o algoritmo para classificação dos estudantes com base nos dados do seu cadastro. O IFMG dispõe de metodologia composta de doze critérios para definir a classificação individual do estudante inscrito em 
determinado edital, cada qual com uma série de condições para geração da respectiva nota final chamada IVS (Índice de Vulnerabilidade Social). Com base no IVS calculado, o aluno recebe um perfil (de "A" até "E"), sendo que estudantes classificados no perfil "A" teoricamente apresentam maior nível de dificuldade para permanecer na instituição em função das suas condições socioeconômicas. $\mathrm{O}$ algoritmo foi implementado utilizando-se o recurso de procedimento armazenado do SGBD MySQL, que possibilitou sua execução independentemente da plataforma requisitante. Para testar o funcionamento e o cálculo realizado pelo algoritmo implementado, a Development Team incluiu, manualmente, um grande conjunto de informações de estudantes participantes de editais antigos na base de dados, permitindo assim a realização de ajustes e correções até que as classificações realizadas estivessem de acordo com a metodologia utilizada pelo IFMG.

A segunda iteração apresentou 96\% de conclusão das atividades ao final do período de quatro semanas de trabalho, refletindo maior integração entre os membros da equipe do projeto e aumento no domínio sobre as regras de negócio envolvidas no processo que estava sendo informatizado. Ajustes solicitados pelo Product Owner na funcionalidade de gestão de documentos dos estudantes fizeram com que o escopo previsto inicialmente fosse alterado, gerando necessidades de mudanças em rotinas já implementadas. Na reunião de retrospectiva, além do levantamento de correções necessárias nas funcionalidades disponibilizadas, foi solicitado pelo Scrum Master que o Product Owner fizesse uma nova análise dos requisitos das funcionalidades que ainda seriam construídas nas iterações seguintes, visando assim reduzir a quantidade de mudanças de escopo durante a execução da codificação.

Na reunião de planejamento do terceiro Sprint foi solicitado pelo Product Owner que a próxima versão do sistema gerada (com os últimos ajustes do segundo Sprint) fosse disponibilizada aos estudantes interessados em já realizar seu cadastro e sanar dúvidas quanto à utilização da ferramenta junto aos Assistentes Sociais dos campi. Para isto, a Diretoria de Tecnologia da Informação (DTI) do IFMG configurou uma máquina virtual com as tecnologias citadas no item 3.3, que funcionou como servidor de serviços e dados da aplicação, contendo dois ambientes denominados "homologação" (para realização de testes antes da finalização de cada versão) e "produção" (para acesso pelos usuários após a homologação de cada versão desenvolvida). A Development Team realizou então a implantação da versão atual do sistema neste ambiente, configurando-o para acesso dentro da estrutura tecnológica da Reitoria do IFMG.

É importante observar que, paralelamente à condução destas atividades técnicas, a Diretoria de Assuntos Estudantis divulgou o novo sistema junto à comunidade acadêmica do IFMG com o apoio da publicação de notícias nos meios oficiais de comunicação, apresentações ao vivo em ambientes virtuais e envios de informes para todos os estudantes que haviam participado dos últimos editais de seleção de bolsistas. Para auxiliar os estudantes na utilização do sistema, em especial na funcionalidade de submissão de documentos digitais, foi designado um servidor de cada campus para atuar como o responsável por este acompanhamento. Diversos treinamentos foram ministrados junto aos servidores que eventualmente viriam a utilizar o sistema, como os Assistentes Sociais, ou mesmo para aqueles que apenas atuariam no apoio aos estudantes. Estas ações foram fundamentais para que a implantação da primeira versão do sistema obtivesse êxito e permitisse que os estudantes logo inserissem seus dados no ambiente. Na primeira semana de disponibilização do sistema, mais de 2.000 estudantes se cadastraram e iniciaram o preenchimento dos seus dados.

Nesta terceira iteração ainda estava prevista a implementação das funcionalidades de cadastro de editais, controle das notificações enviadas pelo sistema e listagem de pendências no cadastro do estudante. O sistema permite a publicação de três tipos de editais: regular (lançados anualmente), fluxo contínuo (para atendimento de demandas específicas) e renovação (para renovação de benefícios ofertados por outro processo). Além disso, cada edital pode oferecer até três tipos de auxílios diferentes, permitindo que o estudante se candidate conforme sua necessidade. Como eram rotinas que não envolviam muitas regras, foi possível encerrar todas as atividades previstas para o Sprint três dias antes do prazo planejado inicialmente. A Development Team aproveitou este avanço para adequar algumas funcionalidades do sistema, tendo como base o retorno dado 
pelos Assistentes Sociais sobre a utilização do mesmo pelos estudantes.

O quarto Sprint contemplou o desenvolvimento da funcionalidade mais importante para os Assistentes Sociais do IFMG, a gestão dos estudantes inscritos em editais. Trata-se de uma página onde o usuário consegue visualizar um grande e variado número de informações sobre todas as inscrições de determinado edital, manipulando-as conforme necessário. Algumas das atividades que o Assistente Social executa nesta rotina são as mesmas que ele fazia anteriormente quando analisava a documentação em papel de cada participante de determinado edital, porém utilizando um ambiente virtual e com informações integradas para the auxiliar. Foi definido um fluxo de situações que cada inscrição deve seguir, contendo inclusive momentos de interação com os estudantes, como, por exemplo, quando o Assistente Social solicita algum tipo de retificação nos dados do cadastro ou em documentos comprobatórios submetidos. Quaisquer modificações realizadas nos dados são automaticamente gravadas pelo sistema para possibilitar futuras pesquisas históricas, indicando o momento do ocorrido e o usuário responsável por cada ato. Com o objetivo de auxiliar o trabalho dos Assistentes Sociais, foi disponibilizada uma ferramenta de pesquisa contendo diversas possibilidades de filtros, fazendo assim que sejam listados apenas aqueles registros que cumpram determinadas condições. A Figura 5 apresenta o fragmento da página onde é realizada a gestão de inscritos em editais.

Figura 5 - Fragmento da página de gestão de inscritos em edital.

\section{SSAE/IFMG Cadastros - Editais - Consultas -}

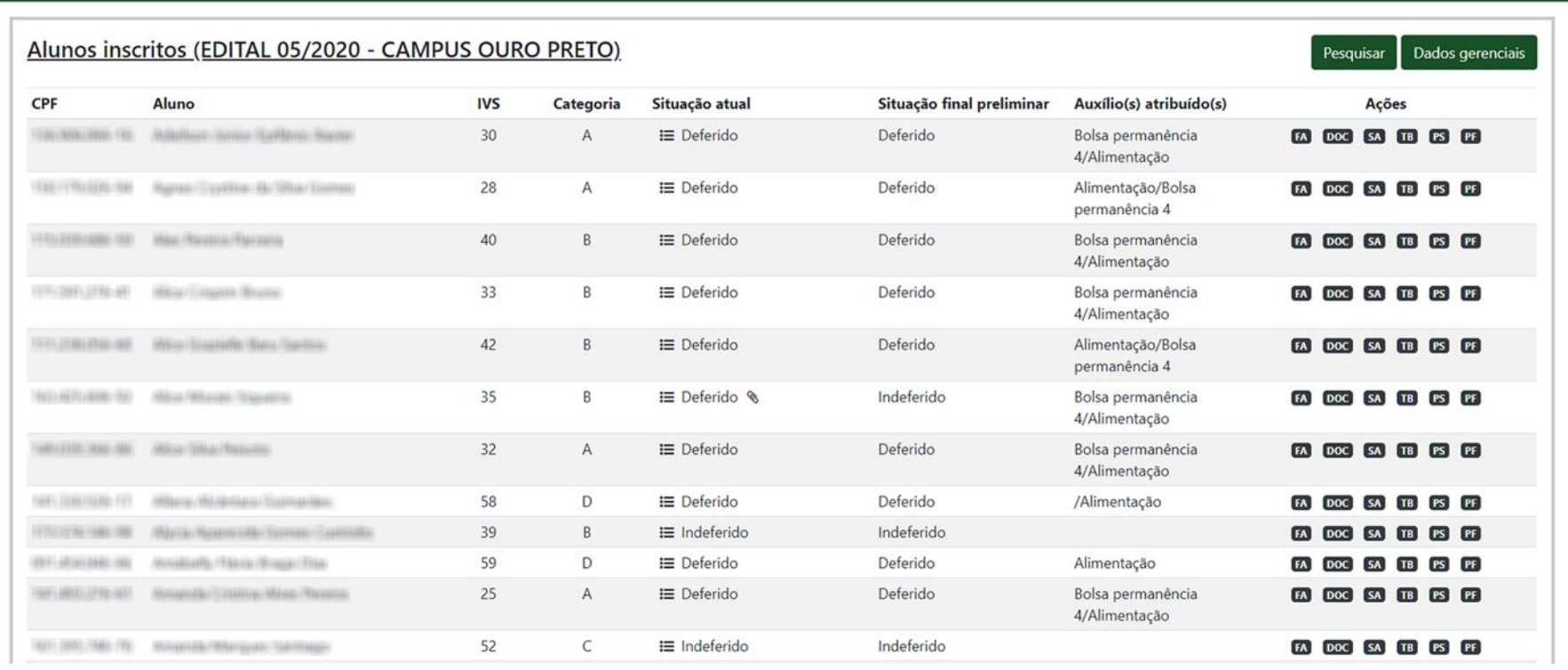

Fonte: Autores (2020).

Mesmo sendo uma funcionalidade com diversas regras de negócio envolvidas, o desenvolvimento foi concluído dentro do prazo de quatro semanas do Sprint. Acredita-se que isso foi consequência, em grande medida, ao contato diário entre os membros da Development Team e o Product Owner, pois as dúvidas surgidas eram rapidamente esclarecidas e cada rotina implementada já era testada e validada sob o ponto de vista de um Assistente Social. Uma dificuldade enfrentada durante a condução das atividades deste Sprint foi não haver modelos de documentação padronizados pelo NASIFMG para todas as etapas do processo de análise de uma inscrição, ao contrário do que ocorreu em funcionalidades implementadas anteriormente, onde um documento ou formulário padrão serviu de base para o início do desenvolvimento.

O escopo do último Sprint estava direcionado para o desenvolvimento de funcionalidades relacionadas à geração de relatórios e planilhas eletrônicas baseadas nos dados coletados via sistema. As rotinas foram construídas permitindo a 
aplicação de filtros complementares, de maneira que o arquivo gerado seja personalizado pelo usuário. Um dos relatórios gerados apresenta o resultado geral de determinado edital, indicando a situação final de cada estudante inscrito. Este relatório otimizou o trabalho de consolidação dos resultados do edital feito pelo NASIFMG, haja vista que antes era necessária a edição de um arquivo para inclusão de dados após a análise de cada inscrição. O processo mais trabalhoso foi a conversão dos dados para o formato de planilha eletrônica, sendo necessária a utilização de uma biblioteca de funções específicas a este fim, chamada PHPOffice ${ }^{l}$. De acordo com o escopo definido para o sistema, ele não teria funcionalidades relacionadas com o gerenciamento do pagamento dos benefícios para os estudantes selecionados, pois o IFMG já possui outro sistema que realiza este controle. Sendo assim, foi implementada nova funcionalidade para gerar uma planilha eletrônica com os dados finais do edital, a qual passou a ser importada pelo sistema de gestão de pagamentos.

As atividades previstas para o último Sprint foram totalmente concluídas em menos de três semanas, então permitindo que a Development Team fizesse correções em algumas funcionalidades desenvolvidas anteriormente, bem como atualizasse as informações constantes no manual do usuário. Após a validação pelo Product Owner e pelos membros do NASIFMG, o sistema foi atualizado no servidor e disponibilizado para todos os usuários. No encerramento desta etapa dos trabalhos foi realizada uma reunião de retrospectiva de todo o projeto, onde foram discutidos e documentados vários pontos positivos e negativos encontrados ao longo da execução das atividades planejadas.

Os primeiros editais regulares cadastrados no sistema começaram a receber inscrições em fevereiro de 2019, sendo este o primeiro ciclo de seleção de bolsistas via sistema informatizado. Naquele momento, a Diretoria de Assuntos Estudantis optou por fazer os processos seletivos de todos os campi exclusivamente via sistema, isto é, o processo anterior baseado em formulários de papel não mais seria utilizado a partir de então. Quando da elaboração deste artigo, em junho de 2020, o sistema continua ativo e operante, auxiliando diretamente na melhoria dos trabalhos relacionados com a seleção de bolsistas do IFMG.

Em termos quantitativos, este projeto gerou alguns indicadores que podem sugerir a sua eficiência dentro do contexto do processo em questão. O sistema atende aos 18 campi do IFMG, possuindo atualmente 9.487 estudantes cadastrados, associados a 19.544 membros familiares destes. Em 2019 foram gerenciados 37 editais com 5.511 inscrições, sendo que destas 4.866 foram pré-selecionadas para análise pelos Assistentes Sociais do NASIFMG. No primeiro semestre de 2020 o sistema auxiliou no controle de 29 editais com 4.088 inscrições, das quais 3.644 foram analisadas. O tempo médio entre a data de abertura do edital e a divulgação dos seus resultados era, no processo manual anterior, de 84 dias corridos; os editais gerenciados pelo sistema apresentaram tempo médio de 41 dias corridos, uma redução de cerca de $51 \%$. Em relação à utilização do sistema, em 2019 foram contabilizados 169.593 acessos, enquanto que no primeiro semestre de 2020 o sistema já autenticou 159.777 entradas. No que tange à digitalização de documentos dos estudantes, o sistema atualmente gerencia um total de 227.592 arquivos (englobando documentos de texto e imagens). Considerando-se somente aqueles documentos pagináveis, estão armazenadas neste momento 796.572 páginas que podem ser acessadas pelos 40 Assistentes Sociais do IFMG cadastrados no sistema.

\section{Considerações Finais}

A implantação e o uso de sistemas de informação normalmente ocasionam diversos impactos no ambiente onde são inseridos, sejam eles positivos ou negativos. Não é nada trivial promover mudanças na forma de atuação das pessoas, sendo que o trabalho com qualquer tipo de sistema informatizado pressupõe a necessidade de adequações e refinamentos até que sua utilização esteja em consonância com o esperado tanto pela organização quanto pelos seus usuários. Por outro lado, quando o sistema é bem planejado e sua implementação atende adequadamente aos requisitos que deram origem às suas funcionalidades,

\footnotetext{
${ }^{1}$ https://github.com/PHPOffice
} 
as chances de sucesso da implantação tendem a ser aumentadas ao mesmo tempo em que os impactos negativos são mitigados. Equilibrar a equação entre o escopo do sistema, sua qualidade, o tempo e os recursos disponíveis, tanto físicos, lógicos e humanos, para sua criação continua sendo um desafio para os gestores de projetos de software.

Os resultados gerados pela informatização do processo de seleção de bolsistas do IFMG indicam que melhorias na gestão pública podem ser pensadas e colocadas em prática para benefício não apenas dos administradores, mas, principalmente, dos indivíduos que utilizam os serviços disponibilizadas pelas instituições públicas. Além dos indicadores numéricos apresentados na seção anterior, é importante ressaltar aquelas melhorias difíceis de serem quantificadas, tais como a imensa redução de papel transitado, os gastos feitos pelos estudantes com cópias de sua documentação comprobatória, a praticidade no processo de análise por parte dos membros do NASIFMG, a rápida divulgação de resultados para os estudantes (fazendo com que a liberação dos valores financeiros possa ocorrer logo em seguida) e a criação de uma base de conhecimentos preciosos sobre os inscritos em editais, como também do processo em si. Este deve ser o papel da tecnologia, atuar como um meio capaz de transformar a realidade das pessoas e organizações, eliminando barreiras e simplificando o que antes era complexo.

O emprego de técnicas da metodologia ágil Scrum, neste projeto, se mostrou viável mesmo para o caso de uma equipe com poucos membros. A divisão do trabalho e seu controle baseado em Sprints com escopos regularmente definidos fez com que todos os envolvidos tivessem uma previsão mais tangível sobre as entregas que seriam realizadas pelo projeto em termos de produtos de software. As cerimônias de planejamento e encerramento de iterações se mostraram valiosos momentos de troca de conhecimentos, não apenas entre os membros da equipe do projeto, mas também para várias outras pessoas envolvidas, notadamente alguns membros do NASIFMG. Ressalta-se, ainda, a participação ativa do Product Owner junto à Development Team durante a execução das atividades previstas nos Sprints, fator fundamental para ampliar o entendimento sobre as características de cada funcionalidade implementada.

As principais dificuldades enfrentadas durante a condução dos trabalhos estão relacionadas à conciliação das atividades do projeto com outras tarefas acadêmicas tanto por parte dos alunos quanto pelo docente envolvido (membros da Development Team). Durante o primeiro Sprint essa situação ficou mais ostensiva, o que impactou negativamente na implementação de todas as funcionalidades previstas para aquele momento. Foi preciso muita disciplina e organização para que as tarefas (profissionais e particulares) dos membros da equipe pudessem ser equalizadas com as demandas do projeto.

A utilização do sistema desenvolvido proporcionou ao IFMG um valioso acervo de dados sobre os seus estudantes. Como não fazia parte do escopo do projeto, não houve, até o momento, a execução de análises estatísticas sobre esses dados. Sugere-se como futuras pesquisas que toda essa base de dados seja analisada com o devido rigor científico para que os gestores da instituição conheçam de forma mais clara o perfil socioeconômico dos seus estudantes, podendo, inclusive, tais resultados embasar melhorias na atual política de Assistência Estudantil do IFMG. Outra possibilidade de estudos futuros está relacionada com o desenvolvimento de um módulo para controle financeiro dos pagamentos de auxílios concedidos via sistema.

Por fim, também é válido destacar que, mesmo no contexto social experimentado pela população atualmente, no qual os trabalhos presenciais em todas as instituições de ensino do país foram suspensos devido à pandemia provocada pelo COVID-19, os processos de seleção de bolsistas de assistência social do IFMG não foram paralisados. Como todas as atividades relativas ao processo foram informatizadas e são suportadas por um sistema de informação que necessita apenas de uma conexão com a internet para ser acessado, é possível afirmar que a tão buscada eficiência na gestão pública pode ser vista como alcançada pela instituição. 


\section{Referências}

Albiero, H. J., \& Silva, M. R. (2018). Economicidade, eficiência e transparência nas compras públicas via pregão eletrônico: estudo de caso dos pregões eletrônicos 42/2012 e 32/2013 realizados pelo IFPR - campus Assis Chateaubriand. ForScience, 6 (1). 10.29069/forscience.2018v6n1.e275.

Batista, E. O. (2013). Sistemas de Informação: o uso consciente da tecnologia para o gerenciamento: Saraiva.

Camões, M. R. S., Severo, W. R., \& Cavalcante, P. (2017). Inovação no Setor Público: Teoria, Tendências e Casos no Brasil: IPEA.

Cavalcante, P., \& Camões, M. R. S. (2015). Gestão pública no Brasil: as inovações configuram um novo modelo? XX Congreso Internacional Del CLAD sobre la Reforma del Estado y de la Administración Pública, https://www.researchgate.net/publication/292984378_Gestao_publica_no_Brasil_as_inovacoes_configuram_um_novo_modelo

Cortes, P. L. (2017). Administração de Sistemas de Informação: Saraiva.

Dias, T. F., Sano, H., \& Medeiros, M. F. M. (2019). Inovação e tecnologias da comunicação e informação na administração pública: ENAP.

Gabardo, A. C. (2015). Criando um e-Commerce com CodeIgniter: Novatec.

Gerhardt, T. E., \& Silveira, D. T. (2009). Métodos de Pesquisa: Editora da UFRGS.

Gomes Filho, A. C. (2018). Gestão de Tecnologia da Informação: Abordagem para o Setor $\quad$ Público. http://repositorio.unicentro.br:8080/jspui/bitstream/123456789/1314/1/GOMES_Gestao_de\%20TI_abordagem_para_setor_publico.pdf

Governo. (2020). Estratégia de Governo Digital 2020-2022. https://www.gov.br/governodigital/pt-br/EGD2020

IFMG. (2020a). Histórico e Missão. https://www.ifmg.edu.br/portal/sobre-o-ifmg/historico-e-missao

IFMG. (2020b). Assistência Estudantil. https://www.ifmg.edu.br/conselheirolafaiete/extensao/assistencia-estudantil

Kon, A. (2019). Inovação nos serviços públicos: condições da implementação do governo eletrônico. Revista Planejamento e Políticas Públicas, 52 (1). https://www.ipea.gov.br/ppp/index.php/PPP/article/view/985/517

Lacerda, S. M. P., \& Helal, D. H. (2019). Governo aberto, transparência e governo eletrônico nas câmaras municipais paraibanas: um estudo multicaso. ForScience, 7 (1). 10.29069/forscience.2019v7n1.e472.

Laudon, K., \& Laudon, J. (2015). Sistemas de Informações Gerenciais: Pearson.

Melegati, J., \& Wang, X. (2019). QUESt: new practices to represent hypotheses in experiment-driven software development. 2nd ACM SIGSOFT International Workshop on Software-Intensive Business: Start-ups, Platforms, and Ecosystems, Tallinn, Estônia. 10.1145/3340481.3342732.

Nunes, R. D. (2017). A implantação das metodologias ágeis de desenvolvimento de software Scrum e Extreme Programming (XP): uma alternativa para pequenas empresas do setor de tecnologia da informação. ForScience, 4 (2). 10.29069/forscience.2016v4n2.e117.

Oliveira, E. L. L. (2017). Inovação na gestão pública federal: análise das relações entre capacidades, modelos e resultados de inovação (Dissertação de Mestrado). Universidade de Brasília, Brasil.

Rabelo, C., \& Viegas, C. (2012). A participação da sociedade no governo eletrônico sob a perspectiva da democracia digital. Revista Argumentum, 13 (1), 225255. http://ojs.unimar.br/index.php/revistaargumentum/article/view/1093

Sordi, J., \& Meireles, M. (2019). Administração de Sistemas de Informação: Saraiva.

Wazlawick, R. (2009). Metodologia para ciência da computação: Elsevier. 